\title{
POLÍTICA Y FUERZAS ARMADAS. CARACTERÍSTICAS Y MISIONES CONSTITUCIONALES DE LAS FF.AA.
}

\begin{abstract}
Las Fuerzas Armadas son servidoras de la patria, de su integridad territorial y de su identidad histórico-cultural. Ellas tienen el carácter de garantes últimos del orden institucional de la República. De nada sirven las instituciones armadas si no hay patria
\end{abstract}

\section{José Toribio Merino Castro}

\author{
Adolfo Paúl Latorre ${ }^{1}$ \\ Egresado de Derecho \\ Universidad Católica del Norte - Coquimbo
}

El presente artículo contiene un resumen de la tesis de investigación del autor, ${ }^{2}$ presentada en agosto de 1999 en la Escuela de Derecho de la Universidad Católica del Norte, sede Coquimbo, para optar al grado de licenciado en Ciencias Jurídicas.

El proyecto de esta investigación fue distinguido con el Premio Ministerio de Defensa Nacional 1998.

La investigación fue elaborada por iniciativa y bajo la dirección de la profesora de Derecho Constitucional -y directora de la mencionada Escuela de Derecho- doña Luz María Reyes Santelices.

Esta tesis fue editada por la Revista de Marina, en octubre de 1999, bajo el título POLÍTICA Y FUERZAS ARMADAS. Características y misiones constitucionales de las FF $A A^{3}$ En cuanto al título del libro - Política y Fuerzas Armadas-, procura ser

1 El autor es capitán de navío de la Armada de Chile, ingeniero naval en armas, oficial de Estado Mayor, profesor militar de Academia en la asignatura de Estrategia, magister en Ciencias Navales y Maritimas con mención en Estrategia por la Academia de Guerra Naval, magister en Ciencia Política con mención en Teoría Política por la Universidad de Chile, destacado colaborador de la Revista de Marina y egresado de Derecho de la Universidad Católica del Norte, sede Coquimbo. Es miembro de la Asociación Chilena de Ciencia Política, del Consejo Chileno para las Relaciones Internacionales y del Instituto Geopolítico de Chile. Ha publicado varios artículos en revistas especializadas y ha participado -como asistente, ponente o comentarista - en diversos seminarios sobre temas relacionados con la Defensa Nacional. Actualmente, ya retirado del servicio naval, se desempeña como práctico autorizado en el puerto de Coquimbo

2 El trabajo de investigación se fundamentó en la pretensión del autor de desarrollar un tema que, junto con satisfacer los requerimientos de una tesis de licenciatura en Ciencias Jurídicas, correspondiera a sus intereses intelectuales y a su experiencia profesional y académica. El autor volcó, en esta obra, gran parte de las inquietudes y experiencias que había ido acumulando durante sus más de treinta años de vida militar.

3 PAÚl Latorre, Adolfo. Política y Fuerzas Armadas. características y misiones constitucionales de las FF AA. Revista de Marina, Valparaiso, 1999, $421 \mathrm{pp}$. 
simplemente una síntesis del más analítico que se dio en su momento a la tesis de licenciatura: Las Fuerzas Armadas: sus características y misiones constitucionales. ${ }^{4}$

\section{Estructura de la obra}

El trabajo que procederemos a reseñar consiste, fundamentalmente, en una tesis de compilación y de análisis de contenido. Ella fue elaborada sobre la base de la revisión de numerosas publicaciones, de las cuales fueron extractados aquellos textos que, por su mayor riqueza conceptual, se consideraron como los más adecuados para pro-

4 El proyecto de investigación fue inscrito bajo el título Las Fuerzas Armadas: sus características y misiones constitucionales; denominación que estaba en consonancia con lo que se pensaba realizar: una tesis de investigación jurídica que se limitaría a analizar lo que la Constitución Política de la República de Chile establece en relación con las características y misiones de las Fuerzas Armadas. Sin embargo, tal título quedaba un tanto estrecho y no reflejaba adecuadamente lo que se hizo en definitiva. En efecto, durante el desarrollo de la investigación, el autor se pudo dar cuenta que - para una mejor comprensión del tema por parte de aquellas personas que no están familiarizada con el Derecho Político- era conveniente agregarle algunos antecedentes políticos, jurídicos y sociales básicos; antecedentes que fueron agrupados en un extenso capítulo de carácter general e introductorio. Asimismo, a fin de presentar un panorama más completo acerca del tema central de la investigación, se estimó conveniente incorporarle un capitulo sobre el Consejo de Seguridad Nacional y otro referido a las proposiciones de reforma de la Constitución que actualmente se debaten en el ámbito político y académico nacional, la mayoría de las cuales altera sustancialmente las caracteristicas y misiones que la Constitución de 1980 le atribuye a las Fuerzas Armadas.

5 "Con modestia, el comandante Paúl describe su obra como fundamentalmente, una tesis de compilación y análisis de contenido. Sin embargo, la profundidad y objetividad con que selecciona, elabora y relaciona una amplia variedad de opiniones respecto a los temas que trata, la constituyen como una obra de gran originalidad. Hasta donde alcanzan mis conocimientos e informaciones acumuladas en muchos años de docencia e investigación, no existe otra publicación comparable a la que estoy presentando..

Uno de los grandes méritos de este trabajo es que presenta en forma ordenada, clara, accesible y exhaustiva toda la problemática que suele interesar a un lector lego en la materia. Explica los problemas juridicos, constitucionales, reglamentarios y valóricos en térmínos comprensibles para un lector naval común; le muestra las diversas posiciones existentes al respecto y le señala las razones que hacen a algunas más válidas que otras. Las notas a pie de página, que en muchos libros suelen contener una oda a la erudición del autor en este libro son fuente de información de gran interés, muchas veces con humor y siempre con imparcialidad y tolerancia.

Pero no nos engañemos, el comandante Paúl es imparcial pero no es neutral. Toda su obra está impregnada de su concepción clásica y tomista del hombre, se afirma en una sólida formación cristiana y enfrenta los diversos temas con la visión recta y sin dobleces propia de su formación naval.

En tiempos en que se relativizan los valores, se duda de la nacionalidad, se cuestiona el valor del honor y se hacen políticamente correctas las modas intelectuales europeas y estadounidenses, este libro nos pone ante el sólido edificio de las instituciones, las costumbres, los valores y las tradiciones nacionales que nos han acompañado desde el nacimiento de la República y nos da poderosas razones que nos motivan a defenderlas y protegerlas, ya que una vez destruidas su ausencia será irremediable.

Recomiendo encarecidamente a todos los oficiales de marina incorporar este libro a su biblioteca personal por ser un documento de inestimable ayuda para resolver interrogantes que con frecuencia surgen en nuestro trabajo. Aclara y rebate una amplia variedad de aseveraciones sin fundamento o más aún de falacias, distorsiones y falsedades que de tanto repetirse y a falta de refutaciones claras, terminan por transformarse en verdades.

Nadie puede exigir a un oficial de marina que domine a cabalidad temas tan diversos y complejos como los que trata el comandante Paúl en su obra, pero es un deber de todos nosotros estar en condiciones de comprenderlos e interpretarlos cuando sea necesario. Este libro nos lleva de la mano a través de ellos con honestidad. rigurosidad y claridad". Fernando THAUBY García, "Presentación del libro Política Y Fuerzas Armadas. Caracteristicas y misiones constitucionales de las FF.AA. Adolfo Paúl Latorre Revista de Marina, Valparaiso. 1999, 421 pp.", Revista de Marina 853, Valparaiso, noviembre-diciembre 1999, pp. 595-596. 
porcionar una visión general de los aspectos más importantes y permanentes de las instituciones armadas.

La obra está conformada por un prólogo, cinco capítulos y un epílogo.

En el Prólogo de su obra, el autor señala que está muy arraigada entre nosotros la idea de que las Fuerzas Armadas son profesionales, jerarquizadas, disciplinadas, apolíticas, no deliberantes y esencialmente obedientes al denominado poder civil. ${ }^{6} \mathrm{Sin}$ embargo, no tenemos muy claros los conceptos contenidos en tales expresiones; el verdadero sentido y alcance de esos términos. Asimismo, hay confusiones en torno al concepto de seguridad nacional y opiniones controvertidas acerca de la función de garantes del orden institucional de la República que nuestra Carta Fundamental le asigna a las Fuerzas Armadas.

Por otra parte, todos nosotros nos formulamos preguntas tales como las siguientes: ¿Qué son las Fuerzas Armadas? ¿Para qué sirven? ¿Qué lugar ocupan en la realidad social? ¿Cuál es su importancia? ¿Cuál es su razón de ser? ¿Cuáles son sus fundamentos políticos y jurídicos? ¿Cuáles son sus características? ¿Cuáles son sus funciones o misiones? ¿Se justifica su existencia y el sacrificio económico que representa la asignación de cuantiosos recursos del presupuesto nacional para su mantenimiento, equipamiento y entrenamiento? ¿Son realmente necesarias las Fuerzas Armadas? ¿Cuál es la relación entre política y Fuerzas Armadas? ¿Cuál es la participación política que les compete? ¿Cuáles son las razones que exigen que ellas — en tanto cuerpos armados, cuanto sus miembros considerados individualmente- deban abstenerse de tomar partido en la lucha política contingente? ¿Cuáles son los derechos políticos que pueden ejercer los militares? ¿Cuál es el papel que las Fuerzas Armadas cumplen en la preservación del régimen político institucional democrático?

También debemos reconocer, como una realidad, el hecho de que en muchos sectores de nuestra sociedad hay personas que desconocen la función militar y que miran con indiferencia, con menosprecio, e incluso con franca aversión y hostilidad a las Fuerzas Armadas; que creen que ellas no tienen razón de ser, que sólo sirven para los desfiles, que son la antinomia de la democracia, que distraen recursos que podrían ser destinados al gasto social y que lo mejor que se podría hacer con ellas sería eliminarlas.

Sobre la base de tales reflexiones, el autor determinó, como objetivo de su trabajo de investigación, aportar algunos antecedentes que contribuyan a aclarar tales conceptos y a dar una apropiada respuesta a las interrogantes planteadas; interrogantes que constituyeron las preguntas directrices que sustentaron la investigación.

6 Las expresiones poder civil, poder público o poder político, reflejan la idea del poder que tiene el Estado para gobernar. Sin embargo, actualmente, a la expresión poder civil se le da una connotación diferente: la de un poder que sólo puede ser ejercido por civiles (utilizando el vocablo civil en su acepción de persona que no es militar) lo que, además de equívoco, expresa la idea de algo inexistente. Si sería aceptable utilizarla como sinónimo de poder político. $Y$ el poder político puede ser ejercido tanto por civiles como por militares. Santo Tomás utilizaba la expresión poder civil para referirse al poder ejercido por los encargados del gobierno de la ciudad, es decir, al poder político. 
El tema genérico, objeto del análisis, es la fuerza militar del Estado. Específicamente, y guiado por las preguntas directrices, el autor pretende describir y explicar lo que son y lo que significan las instituciones militares, las características y misiones que nuestro ordenamiento jurídico fundamental les asigna, y el papel que las Fuerzas Armadas cumplen en la preservación del régimen político institucional democrático. El trabajo consistió, en consecuencia, en examinar los fundamentos de las instituciones militares y en trazar la influencia que ellos tuvieron en el constituyente de 1980 al momento de establecer las características y misiones de las Fuerzas Armadas en la nueva Carta Fundamental.

El tema de la investigación es de un carácter más bien abstracto, de interés permanente y, a la vez, de delicada actualidad; lo que siempre hace más difícil y de alto riesgo intelectual el estudio que supone. Aun cuando está consciente de este riesgo, a fin de adentrarse en el meollo del tema y de ilustrar mejor algunos conceptos, el autor ha debido, ineludiblemente, referirse a aspectos concretos de nuestra experiencia histórica cercana y a situaciones que forman parte del actual debate político-jurídico.

Para alcanzar los objetivos propuestos, el autor procedió —en lo principal- a efectuar un análisis de los textos constitucionales que establecen las características y misiones de nuestras Fuerzas Armadas, sobre la base de lo que en su oportunidad expresaron los miembros de la Comisión de Estudio de la Nueva Constitución Política de la República ${ }^{7}$ y las opiniones que al respecto han emitido diversos constitucionalistas y otros académicos especializados en asuntos relacionados con la defensa nacional.

El autor señala finalmente, en su prólogo, que espera que el contenido de su trabajo pueda ser útil para aquellas personas que no conocen o no comprenden la razón de ser de los cuerpos armados y que tengan el sincero deseo de informarse acerca de ellos.

En tiempos en que se niega la validez y la necesidad de las FF.AA.; y en que se promueve una amplia variedad de aseveraciones sin fundamento, de falacias, distorsiones y falsedades acerca de ellas, esta obra pretende describir y explicar apropiadamente lo que son las FF.AA., su naturaleza, sus fundamentos políticos y jurídicos, sus características y peculiaridades, sus funciones y misiones, la nobleza de la función militar, la vital función que cumplen en una sociedad política y la importancia que ellas tienen para garantizar la paz, el orden, la libertad y la seguridad de la nación. De este modo, espera contribuir al entendimiento de aquel importante y desconocido e incomprendido sector de nuestra realidad chilena y, así, propender a la cohesión y a la unidad nacional; unidad de la que dependen, en gran medida, la pujanza y la vitalidad de las naciones.

Actas Oficiales de la Comisión de Estudio de la Nueva Constitución Política de la República, Santiago, 24 septiembre 1973 al 5 agosto 1978 (417 sesiones, contabilizadas 14 que no se celebraron por falta de quórum) Hasta la sesión $245^{\circ}$, celebrada el 19 de agosto de 1976, dicha comisión fue llamada Comisión Constituyente: a partir de la sesión siguiente, del 21 de septiembre de 1976, se denominó Comisión de Estudio de la Nueva Constitución Política de la República. 
Asimismo, espera que su obra contribuya a enriquecer el actual debate políticojurídico en torno a los cuerpos armados y que conduzca a nuevas investigaciones en este campo, por mucho que ello resulte crítico para su punto de vista.

En el Capítulo I, Política, Derecho y Fuerzas Armadas, se describen ciertos antecedentes políticos, jurídicos y sociales básicos, que nos ayudan a comprender la razón de ser de las Fuerzas Armadas, sus características y sus misiones.

Este capítulo fue dividido en tres grandes apartados, en los que se tratan temas tales como: el bien común, la política, el Derecho, la nación, el Estado, la sociedad y la potestad política, la democracia, la legitimidad del gobierno y el derecho de rebelión; el conflicto social, la política internacional, la estrategia, la disuasión, ${ }^{8}$ la guerra; el sentido de la función militar, el uso legítimo de la fuerza, la defensa nacional y la seguridad nacional; las relaciones civiles-militares, la función política de las Fuerzas Armadas y las intervenciones militares.

El Capítulo II, titulado Constitución Política y Fuerzas Armadas, está dedicado al análisis de la consagración constitucional de las Fuerzas Armadas y de los principios organizativos de la fuerza militar en la nueva institucionalidad.

En el Capítulo III. Características constitucionales de las Fuerzas Armadas, se analiza el carácter peculiar de la profesión militar, la neutralidad política y el apoliticismo castrense, ética y valores en las Fuerzas Armadas, la disciplina, la obediencia y la no deliberancia. ¿Qué significa que las FF.AA. sean apolíticas, obedientes y no deliberantes? ¿A quién se debe obediencia? ¿En qué condiciones no se debe obediencia? ¿Qué debemos entender por FF.AA. profesionales?

El Capítulo IV. Misiones constitucionales de las Fuerzas Armadas, está dedicado a analizar las misiones que la Constitución Política de 1980 le asigna a las Fuerzas Armadas: existen para la defensa de la patria; son esenciales para la seguridad nacional; garantizan el orden institucional de la República.

En este capítulo se analizan aspectos tales como los siguientes: la defensa de la patria, la unidad nacional, la soberanía, la independencia, la integridad territorial, el concepto de tradición, la salvaguarda de los valores permanentes de la nación; la seguridad nacional en la Constitución Política; la defensa del orden institucional, las principales objeciones a la misión de garantes del orden institucional atribuida a las Fuerzas Armadas y los argumentos que la justifican.

En el Capítulo V. Consejo de Seguridad Nacional, se examinan las características, funciones y atribuciones de dicho Consejo.

8 La disuasión consiste en amenazar al adversario con un daño mayor que el beneficio que espera alcanzar o un sufrimiento que no esté dispuesto a aceptar. Por ello es un error pretender disuadir basándose sólo en medidas defensivas, tratando de hacerle más difícil el triunfo al adversario. Con las medidas disuasivas hay que hacer temer al adversario su propia victoria. Sólo una alta capacidad ofensiva puede impedir que un adversario ambicioso lleve a cabo sus propósitos. 
Como última parte de esta obra, un Epilogo, en el cual se exponen las diversas proposiciones de Reforma de la Constitución y los argumentos más importantes que se esgrimen, tanto a favor como en contra de dichas reformas. En este epílogo se refieren sucesos muy relacionados con el tema principal: las proposiciones de reforma de la Constitución que actualmente se debaten en el ámbito político y académico nacional; la mayoría de las cuales altera sustancialmente las características y misiones que la Constitución de 1980 le atribuye a las Fuerzas Armadas. ${ }^{9}$

\section{Las FF.AA. existen para la defensa de la patria}

En relación con estas misiones y con los valores que las FF.AA. han jurado defender, el almirante Merino expresó, con razón, que "las Fuerzas Armadas son servidoras de la patria, de su integridad territorial y de su identidad histórico-cultural. Ellas tienen el carácter de garantes últimos del orden institucional de la República" ${ }^{10}$

Sin embargo, hay en Chile numerosos líderes de opinión que no concuerdan con tales plateamientos y que cuestionan conceptos táles como la náción, la pátrià, la a autóridad, el Estado y la seguridad nacional; o valores tales como el honor, el valor, la lealtad, la abnegación y el sacrificio. En tiempos en que se tiende a hacer prevalecer el materialismo y el hedonismo; en que se condena la violencia venga de donde venga, ${ }^{11} \mathrm{y}$ en que diversos sectores interesados se empeñan en presentar a las FF. AA. como instituciones perversas, y a sus miembros como encarnación de la violencia, del odio y del abuso; el autor pretende, a través de su obra —que es en gran parte un testimonio, puesto que las reflexiones y afirmaciones que formula en ella están avaladas por una experiencia de más de treinta años de vida militar - mostrar los valores que son parte, desde siempre, de la cultura y formación de los integrantes de las FF.AA. de Chile.

9 "Debe tenerse presente que si las FF.AA. son la instancia final a que se recurre cuando una crisis política amenaza la sobrevivencia de la nación, se requiere extrema sagacidad y cautela para encauzar cualquiera evolución constitucional. Un paso en dirección equivocada puede debilitar y finalmente destruir a las FF.AA., llevando al país a la anarquía o a la subyugación extranjera ". Voto de minoría suscrito con fecha $1^{\circ}$ de julio de 1980 por los consejeros del Consejo de Estado señores Carlos Cáceres Contreras y Pedro Ibáñez Ojeda, al informe emitido por el Consejo de Estado recaído en la consulta formulada por S.E. el Presidente de la República acerca del anteproyecto sobre nueva Constitución Politica del Estado; en documento oficial del Consejo de Estado, p. 32

10 MERINO Castro, José Toribio. Discurso pronunciado en la reunión inaugural del período legislativo 19881999. 17 de marzo de 1988. Folleto impreso por TT.GG. Instituto Geográfico Militar de Chile, pp.10, 20.

11 La paz social sólo puede alcanzarse mediante la imposición del orden recto, lo que ordinariamente lleva consigo la necesidad de aplicar violencia para impedir la acción de quienes subvierten ese orden. La fuerza al servicio de la comunidad, contra la agresión injusta o contra la resistencia injusta a la ordenación social, es un medio al servicio de la paz. De lo expuesto se puede inferir la completa improcedencia y la carencia de base moral de que adolecen las condenas universales de la violencia

La defensa de los derechos humanos es usada en forma dialéctica para desarmar sicológica y moralmente a quienes, por deber de autoridad, están obligados en justicia a emplear la violencia para reprimir a quienes subvierten el orden natural, único fundamento para una verdadera concordia social. 
El autor conoce, desde el interior de una institución militar, lo que son las FF.AA., los ideales que las sustentan y el espíritu que las anima. Esos ideales y ese espíritu se pueden sintetizar en cuatro palabras: servir a la patria.

La patria es el valor fundamental de quienes profesan la carrera de las armas; valor cuestionado a veces, hoy como en el pasado, pero que mueve a los hombres desde la antigüedad. Y es un valor tan grande, que lleva a los hombres a dar su vida por él; y si algo se valora más que a la propia vida, es porque se considera superior a ella. Y lo superior a ese ser limitado que es el hombre resulta, para él, en algún modo, incomprensible y misterioso.

Confusos prejuicios impiden a algunos acercarse intelectualmente a la esencia de la patria, que comprende bienes diversos: físicos, como el territorio; humanos, como los hombres que son sus hijos; históricos, culturales y morales.

Pero la existencia de bienes, implica la de un sujeto que les asigna un valor. Por ello es posible afirmar que la patria es un producto del amor. La patria es lo que se ama; es el sentimiento de un lazo común en el presente y en el pasado, que junta en una unidad corazones y conciencias; es la comunidad moral e histórica de la que nos reconocemos parte; es la conciencia y el sentimiento de la nación.

La patria es en gran parte la obra de todos los que la sienten; es como el ser amado, que, para serlo, necesita que alguien lo ame. Pero la patria no es algo abstracto: es la tierra en que nacimos y nos formamos, son sus hombres, sus valores, todo aquello que supone su defensa. Por ello es la patria un valor supremo, que trasciende al hombre y que es, evidentemente, algo más elevado que la política contingente o que la política partidista.

La patria designa a la heredad completa del hombre; ella no sólo está formada por los ciudadanos que en un momento dado habitan en su territorio, sino por la memoria y el recuerdo de cuantos chilenos, a través de la historia, escribieron en ella páginas brillantes y nos han legado su nombre y sus hazañas. $Y$ está formada, también, por la esperanza en quienes han de sucedernos y continuarán el relato interminable de nuevos esfuerzos, de nuevos sacrificios. Por eso, al defender la patria, defendemos nuestro mañana no nuestro ayer.

Las Fuerzas Armadas están exclusivamente consagradas al servicio de la patria, quehacer común de los chilenos de ayer, hoy y mañana. Ellas tienen clara conciencia de estos conceptos fundamentales, así como del trascendental papel que les corresponde en la seguridad nacional y en la garantía del orden institucional de la República.

Los militares son los guardianes de la patria. Guardianes frente al exterior, sin duda, y en el interior también tienen misiones que cumplir; pero su principal guardia, debe estar encaminada a que no se desvirtúe la noción de patria; aquel nexo espiritual que da vida a la nación y que constituye el alma nacional. En este sentido, debemos recordar aquel pasaje del Evangelio que dice: No tengan miedo de los que les puedan matar el cuerpo: sólo teman a quien les pueda matar el alma. 
Es por ello que el mayor peligro actual es el cambio cultural, que va penetrando, corrompiendo y cambiando la sociedad, ya sea consciente o inadvertidamente.

Y esto es así, porque si el cambio cultural consigue que se olviden aquellos valores esenciales de la tradición chilena, aquellos valores que han ido formando a nuestra nación; si consigue que la moral de la sociedad tome rumbos distintos de aquellos que hemos recibido; si llega a cambiar nuestra forma de ser y nuestro modo de reaccionar; en vez de un ciudadano amante de su patria, nos encontraremos con un individuo sin voluntad y sin coraje, dispuesto a la resignación y a la entrega. Podría ocurrir, entonces, que las Fuerzas Armadas no pudieran cumplir con su misión al no existir una patria a la cual defender.

$Y$, como bien dijo el almirante José Toribio Merino Castro: "de nada sirven las instituciones armadas si no hay patria". ${ }^{12}$

\section{Conclusiones}

Finalmente, recapitulando lo expuesto y a modo de conclusión, en un apartado denominado Reflexiones Finales, el autor expresa:

El constituyente de 1980 - recogiendo nuestra experiencia histórica y con una acertada visión de futuro- reconoció a las Fuerzas Armadas como uno de los pilares básicos del Estado y su carácter de instituciones fundamentales de la República. Por ello, junto con establecer en el texto constitucional sus características y misiones, reguló tanto su participación política como su contribución a la seguridad nacional y a la estabilidad institucional.

La Carta de 1980 inserta a las Fuerzas Armadas en la nueva institucionalidad de una manera equilibrada y coherente: por una parte dispone que están subordinadas al orden institucional y, por otra, que son dependientes del Presidente de la República en las materias y en la forma que ella establece.

La democracia no significa el imperio irrestricto de las mayorías. Por eso, una verdadera democracia contempla ciertos mecanismos o resguardos para que éstas no puedan hacer lo que quieran. Uno de esos resguardos está representado por las disposiciones constitucionales que no permiten, a autoridad política alguna, disponer discrecionalmente del alto mando de las Fuerzas Armadas y aquellas que establecen la inamovilidad relativa de sus Comandantes en Jefe. Estas disposiciones constituyen mecanismos prudentes y necesarios en vista de la responsabilidad que les compete a los cuerpos armados de garantizar el orden institucional de la República. La participación de las Fuerzas Armadas en el Consejo de Seguridad Nacional constituye la expresión funcional de esa responsabilidad.

\footnotetext{
${ }^{12}$ MERINO Castro, José Toribio, Bitácora de un Almirante. Memorias, Andrés Bello, Santiago, 1998, p. 258.
} 
La Constitución Política de 1980 — a diferencia de las anteriores - le asigna explícitamente a las Fuerzas Armadas un papel político, mas no en aspectos de política contingente o en asuntos de gobierno, sino que en aquellos asuntos que dicen relación con lo superior y más permanente del Estado — con los altos intereses de la nación: la defensa de la patria, la seguridad nacional y el resguardo del orden institucional de la República-; función política que ejercen, principalmente, a través de su participación en el Consejo de Seguridad Nacional.

El Consejo de Seguridad Nacional representa un instrumento muy valioso en la relación civil-militar y responde a claras razones de conveniencia nacional. Una de las grandes finalidades del Consejo es la de evitar que se llegue a circunstancias tan críticas en la vida nacional que hagan necesaria la intervención de las Fuerzas Armadas. Este Consejo es, además, un legítimo y transparente cauce de expresión de los cuerpos armados de la República, un lugar de encuentro de las más altas jerarquías de la institucionalidad nacional, un contrapeso al poder presidencial, un mecanismo superior de descompresión política, y una instancia de solución a conflictos entre autoridades u órganos de rango constitucional. Su existencia, por lo tanto, contribuye a evitar o a atenuar eventuales conflictos y a mantener o a favorecer la estabilidad institucional. Por consiguiente, el debilitamiento, la eliminación o la desnaturalización de este órgano sería altamente inconveniente para el interés nacional.

Las Fuerzas Armadas no son apolíticas, sino apartidistas - lo que es muy diferente- puesto que ellas se deben a la nación, que es lo permanente y que está por sobre y más allá que los partidos. Los partidos, como su nombre lo indica, son un factor de división; las Fuerzas Armadas, por el contrario, son un factor de unión en torno a los valores más sagrados de la patria.

Las Fuerzas Armadas son no deliberantes sólo en aspectos que dicen relación con la política contingente, con la política de los partidos; mas no en las materias relativas a sus funciones específicas o en aquellos aspectos que atañen directamente a su profesión y a los altos intereses nacionales.

Dadas las peculiares características de los cuerpos armados, la Carta de 1980 les otorga un cauce específico para tal deliberación: el Consejo de Seguridad Nacional, actividad que desarrollan representadas por sus más altos mandos.

Las misiones asignadas por la Carta de 1980 a las Fuerzas Armadas y de Orden constituyen una garantía para los intereses vitales de la nación, así como para el resguardo del ordenamiento institucional y de los derechos fundamentales de las personas. La misión de las Fuerzas Armadas no se limita a la defensa de la integridad territorial del Estado.

Las proposiciones de reforma de la Constitución le restan atribuciones a las Fuerzas Armadas, aumentan el poder de los partidos políticos y debilitan los factores de equilibrio, que son la base de la estabilidad política e institucional de la República. 
Las Fuerzas Armadas, por la naturaleza de sus funciones, tienen una permanente y significativa participación en la vida nacional, fundamental para que la sociedad pueda desarrollar sus actividades con estabilidad y tranquilidad.

No parece razonable concebir unas Fuerzas Armadas alejadas de nuestra experiencia histórica, sin reconocer el gravitante papel y la decisiva influencia que ellas tienen en nuestro devenir como nación libre y soberana, y sin considerar nuestras tradiciones, costumbres y creencias. ${ }^{13}$

La política es una actividad social que se basa en realidades. Una de ellas es el hecho de que las Fuerzas Armadas siempre ejercen una función política. ${ }^{14} \mathrm{La}$ Constitución de 1980, reconociendo tal realidad, le otorga a los cuerpos armados un cauce de expresión y de participación política a través del Consejo de Seguridad Nacional.

Con todo, institucionalizado o no, el papel de las Fuerzas Armadas seguirá siendo el de garantes, en última instancia, del orden institucional de la República; salvo que ellas dejen de ser lo que son, que ellas dejen de ser lo que tienen que ser.

Al no contar con la presencia fuerte y vitalizadora de las Fuerzas Armadas nuestra nación caería en la indefensión. Ellas constituyen — por tal razón- una institución que debemos cuidar. Los miembros de la comunidad nacional deben apoyar y fortalecer a sus Fuerzas Armadas, puesto que si se deteriora o se destruye ese elemento cohesionador de la nacionalidad, esa reserva moral de la nación, ese precioso e inestimable rescoldo de legitimidad, ${ }^{15}$ la nación dejaría de contar con ese valiosísimo instrumento.

13 "Todos los grandes hechos históricos del Chile del siglo XX, que han conformado el Chile moderno, tienen un ingrediente militar". VIAL CORREA Gonzalo, "Perfil histórico de la democracia chilena", en edición especial de la revista Política, "Bases del Régimen Democrático", Instituto de Ciencia Política, Universidad de Chile. Santiago, enero de 1987, tomo I, p.56.

Al respecto, diversos autores han señalado que los institutos armados tienen una naturaleza esencialmente política y que la no consideración de este factor conduce a confusiones y a errores en los análisis que se realizan acerca del papel que los militares desempeñan en una sociedad. Cfr. E. FINER Samuel, Los militares en la política mundial, Sudamericana, Buenos Aires, 1969.

15

"Cuando se habla de Fuerzas Armadas lo primario no son las armas ni siquiera las fuerzas. Esto es paradójico. Lo primario es la organización, es el orden, es la cadena jerárquica, es, en definitiva, la autoridad; pero la autoridad como poder moral, es decir, a última hora, como poder espiritual. Las Fuerzas Armadas, si lo son, lo que no pueden ser jamás es fuerza bruta, en modo alguno; si las Fuerzas Armadas se reducen a fuerza bruta, entonces ya no son lo que son. ya no son lo que tienen que ser, justamente es la violación radical de lo que las constituye

Estamos en una época de crisis, una crisis dentro de la sociedad - a veces dentro de un complejo de sociedades- Yo tengo la convicción de que estamos en un mundo definido por una crisis general de legitimidad... Pues bien, en épocas de crisis social y especialmente de crisis de la legitimidad, las Fuerzas Armadas frecuentemente son el resto de la legitimidad: por lo que tienen de organización jerárquica, por lo que tienen precisamente de autoridad, suelen ser lo que queda, el resto de la legitimidad de autoridad en crisis. Yo creo que esto es lo más valioso que tienen, y lo más necesario para una sociedad

Diríamos así que en este sentido, en estas circunstancias, las Fuerzas Armadas representan el rescoldo de una legitimidad más amplia que ha estado comprometida, o que está apagada; el rescoldo para volver a encenderla A veces se puede, sobre las cenizas, sobre el rescoldo de un fuego que ha ardido, volver a encenderlo y pueden brotar nuevamente las llamas. Esta es la función capital que tendría ese precioso, inestimable rescoldo de 
Adolfo Paúl Latorre - Política y Fuerzas Armadas Características...

con ese verdadero seguro $-y$, a veces, último recurso- para conjurar amenazas y repeler agresiones externas, o para enfrentar graves situaciones de subversión interna que pongan en riesgo la estabilidad institucional de la República e, incluso, la supervivencia misma del Estado. ${ }^{16}$

Y la mejor manera de cuidarlas, desde el punto de vista político, es respetando la autonomía y los mecanismos que la Constitución les confiere, tanto para sus necesidades internas como para manifestar sus opiniones. Toda otra opción constituye una ceguera y una falta de sentido nacional que no se aviene con la indispensable sensatez que reconoce la división y el equilibrio de poderes, y el mutuo respeto de las instituciones, como condiciones esenciales para el sano funcionamiento del Estado y cuya consolidación definitiva es el deseo común, que debe superar las mezquinas pasiones del momento.

Lo verdaderamente importante no es perseguir una perfección formal de la Constitución escrita, sino que buscar el fortalecimiento del patriotismo, la responsabilidad y las demás virtudes morales de los ciudadanos. Lo que cuenta, en definitiva, es el vigor del alma nacional, no la perfección formal del Estado.

Las Fuerzas Armadas son fundamentales para una nación altiva, que tiene la firme voluntad de defender su libertad y soberanía, que es respetuosa de su historia, de su cultura y de sus tradiciones, y que desea proyectarse hacia un futuro mejor.

la legitimidad". MARIAS Julián, "El papel de las Fuerzas Armadas", Reconquista 433, Madrid, marzo 1987. p.14.

Las instituciones armadas son "el último circulo jerarquizado de la sociedad, capaz de salvar de su disolución a una comunidad política organizada". OEHLING Hermann, La función política del ejército, Memorial del Ejército, Santiago, 1977, p.18.

Las Fuerzas Armadas son "una institución especializada para resguardar y asegurar, en última instancia, los valores sagrados de una sociedad" BIDERMAN Albert D, "What is Military?", en A Handbook of Facts and Alternatives, University of Chicago Press, 1967; citado por YARMOLINSKY Adam, The Military Establishment, Harper Colophon Books, New York, 1971, p.3. 